\title{
A visionary scientist selects clinicians for clinical research
}

\author{
Friedrich C. Luft $^{1}$
}

Published online: 31 March 2016

(C) Springer-Verlag Berlin Heidelberg 2016

We celebrate Detlev Ganten's 75th birthday late this March (Fig. 1); we hope he is celebrating too. Detlev Ganten is not only founding editor of the Journal of Molecular Medicine and still active in this capacity, he is also the initial director of the Max-Delbrück Center for Molecular Medicine (MDC) Berlin-Buch. The MDC traces its heritage to the KaiserWilhelm Institute für Hirnforschung, officially founded 1931. The collaboration between Nikolai TimofejewRessovsky, Karl Zimmer, and Max Delbrück that resulted in placing genetics on a molecular footing has been told many times. When the institute was reconstituted after German reunification, Detlev Ganten was given the task of resurrecting the MDC to world-class. And so he did; for 13 years, he was at the helm. Since its founding, 25 years have passed and the MDC has performed even beyond Detlev Ganten's expectations. Of course, since his first two publications appeared in Nature [1] and in Science [2], he probably believes that such publications are easy, as they were for him.

Detlev Ganten gave the MDC a unique mission, namely pursuing the highest caliber of disease-oriented (clinical) biological research focusing on the basic mechanisms and molecules of relevance in health and disease and emphasizing the most advanced methodologies in cell biology, genetics, and genomics. He was less interested in the topic and wisely supported the idea that the MDC should pursue a broad spectrum of problems comprising the current chronic scourges, namely cardiovascular disease, cancer, and neurodegenerative

Friedrich C. Luft

luft@charite.de

1 Experimental and Clinical Research Center, Charite Medical Faculty and the Max Delbrück Center for Molecular Medicine,

Lindenbergerweg 80, 13125 Berlin, Germany disorders. Similarly circumspect, the MDC has maintained this broad base until the present day.

Another unique decision Detlev Ganten made was to include clinicians in the field of MDC senior scientists. As the institute had a tradition of encompassing clinical departments since the time of Oskar and Cécile Vogt, the decision was made easier. The institute had continued that tradition and before German reunification had worked intensively with a clinic dedicated to cancer and a clinic for cardiovascular diseases in the framework of the "Academy of the Sciences". However, although the clinics were still there, the framework was gone and to continue the concept in conjunction with the two medical schools Berlin had in 1991 was difficult. Furthermore, the mission Detlev Ganten espoused was not necessarily commensurate with the usual department chairmanships in academic medicine. Clinical excellence, teaching, and research were the appropriate criteria of the time; however, Detlev Ganten wanted the order and emphasis revised and reversed. Research at an internationally competitive level was to receive priority, yet the clinical departments also had to work; the patient care had to be excellent, and the teaching mission was not to be ignored. He found his clinicians and the search also underscores the value of personal relationships when making personnel decisions.

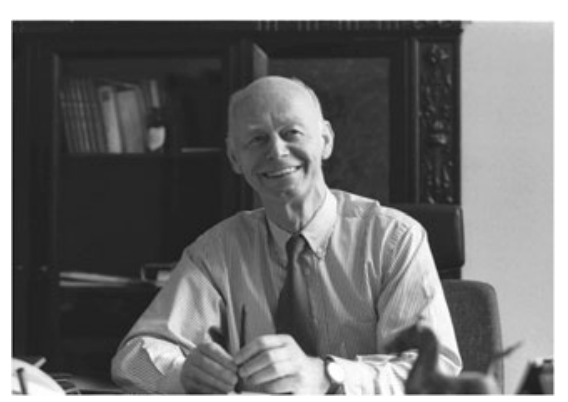

Fig. 1 Detlev Ganten with boundless optimism and enthusiasm, always smiling and he means it 
The choices came from persons that Detlev Ganten knew well, namely from Heidelberg. Rainer Dietz (cardiologist), Bernd Dörken (oncologist), and Peter Schlag (cancer surgeon) were all on the University of Heidelberg's medical faculty. I was not but had spent a sabbatical year in Detlev Ganten's pharmacology research group in Heidelberg. Detlev Ganten claims I showed up 1 day in his office riding my bicycle (true) wearing a helmet with rear-view mirror (not true). I thought helmets were for sissies; my wife has since convinced me otherwise. The research in Detlev Ganten's laboratory was stimulating. The role for a renin-aniotensin system in the brain conducting cardiovascular regulation, salt-and-water appetite, and even controlling energy metabolism is now well established [3, 4]. Natriuretic peptides had been discovered, but developing an assay to measure natriuretic peptides brought this line of research into the clinical arena [5]. Detlev Ganten's generosity of authorship also made itself apparent. The development of transgenic cardiovascular models provided clinician/scientists with animal models of diseases that could be tested in countless ways [6]. Saying "no" to such a challenge was not an option.

Establishing the clinician/scientists as MDC group leaders was not a problem. Finding the clinical departments medical school affiliations proved to be much more of a challenge. Finally, the Free University of Berlin agreed to accept the Robert-Rössle Clinic for Oncology and the Franz-Volhard Clinic for Cardiovascular Disease in Berlin-Buch as a regular part of its medical school facility.

The two clinics did surprisingly well. The clinical care was maintained at a very high standard, the medical students and house-staff trainees met career goals, and an entire generation of young clinician/scientists was trained; these physicians continue productive careers in academic medicine today. The MDC provided expertise in basic science, collaborative opportunities, and an infrastructure that existed nowhere else in Germany. As an example, the clinical departments each and independently produced a keynote paper 15 years after their founding [7-10]. Detlev Ganten's vision of the Robert-Rössle Clinic and the Franz-Volhard Clinic adjacent to the MDC campus could not survive the expediencies of later times. Nonetheless, true to his boundless optimism, he was instrumental in fostering the founding of the Experimental and Clinical Research Center (ECRC) on the campus that remains the interface between the MDC, the Charite Universitätsmedizin Berlin and medical education in Berlin. In order to further strengthen clinical translational research, he accepted in 2004 to become CEO of the Charite. During this time, he managed to merge the Medical Faculty and Hospitals of the Free University (West Berlin) with the Medical Faculty and Hospitals of the Humboldt University (East Berlin) to the united "Charité Universitätsmedizin Berlin" and laid the foundations of the Berlin Institute of Health (BIH) an umbrella organization, supporting the cooperation between the Charité and the MDC. The BIH now serves as a model for clinical research and translation from bench to bedside to population health in the country.

Detlev Ganten is a man of courage and imagination. These two qualities are necessary for effective leadership. His contributions to clinical research are legion. However, what he moved in terms of bringing clinicians to science are in my view even more important. His foresight molded my career and I am certain I speak for my clinician/scientist colleagues.

Respectfully,

Friedrich C. Luft

\section{References}

1. Ganten D, Hayduk K, Brecht HM, Boucher R, Genest J (1970) Evidence of renin release or production in splanchnic territory. Nature 226:551-552

2. Ganten D, Minnich JL, Granger P, Hayduk K, Brecht HM, Barbeau A, Boucher R, Genest J (1971) Angiotensin-forming enzyme in brain tissue. Science 173:64-65

3. Ganten D, Hermann K, Bayer C, Unger T, Lang RE (1983) Angiotensin synthesis in the brain and increased turnover in hypertensive rats. Science 221:869-871

4. Bader M, Ganten D (2008) Update on tissue renin-angiotensin systems. J Mol Med (Berl) 86:615-621

5. Lang RE, Thölken H, Ganten D, Luft FC, Ruskoaho H, Unger T (1985) Atrial natriuretic factor - a circulating hormone stimulated by volume loading. Nature 314:264-266

6. Mullins JJ, Peters J, Ganten D (1990) Fulminant hypertension in transgenic rats harbouring the mouse Ren-2 gene. Nature 344:541544

7. Lamprecht B, Walter K, Kreher S, Kumar R, Hummel M, Lenze D, Köchert K, Bouhlel MA, Richter J, Soler E (2010) Derepression of an endogenous long terminal repeat activates the CSF1R protooncogene in human lymphoma. Nat Med 16:571-579

8. Stein U, Walther W, Arlt F, Schwabe H, Smith J, Fichtner I, Birchmeier W, Schlag PM (2009) MACC1, a newly identified key regulator of HGF-MET signaling, predicts colon cancer metastasis. Nat Med 15:59-67

9. Hauck L, Harms C, An J, Rohne J, Gertz K, Dietz R, Endres M, von Harsdorf R (2008) Protein kinase CK2 links extracellular growth factor signaling with the control of p27(Kip1) stability in the heart. Nat Med 14:315-324

10. Machnik A, Neuhofer W, Jantsch J, Dahlmann A, Tammela T, Machura K, Park JK, Beck FX, Müller DN, Derer W (2009) Macrophages regulate salt-dependent volume and blood pressure by a vascular endothelial growth factor-C-dependent buffering mechanism. Nat Med 15:545-552 